NCSR 2016 August 17 - 18

Death, Bereavment and Memory

\begin{abstract}
The Dark Night of the Soul

Art Film, Bereavement and Complicated Audience Responses
\end{abstract}

In a society characterized by mediatization people are to an increasing degree dependent on mediated narratives as a primary means by which we make sense of our experience through time and our place in life (Hoover 2006, Lynch 2007, Hjarvard 2008, Hjarvard \& Lövheim 2012). There is a growing field of research evolving around the idea that art could play a therapeutic role in various human context as well as act as a catalyst for experiences of deeper meaning. Film scholar Daniel Brodén maps out preliminary findings in several case studies within this field where individuals seem to engage in highly idiosyncratic manner (Brodén forthcoming). This is also the case in the presented project below. The participants reacted strongly to the contemplative movie Night, in surprisingly negative ways that require careful considerations. The impression of the short film from those present in the bereavement groups were essentially adverse. The purpose of this presentation is to interpret the complicated response to the film. I will also problematize how a short contemplative film could serve as a resource for some individuals in a life crisis process as well as why it fails to do so for others.

\title{
Tomas Axelson
}

Associate professor Religious Studies

School of Humanities and Media

Dalarna University, 79188 Falun, Sweden 